\title{
Estrogen disorders: Interpreting the abnormal regulation of aromatase in granulosa cells (Review)
}

\author{
TING LIU ${ }^{1}$, YIFEI HUANG ${ }^{2}$ and HUI LIN ${ }^{1}$ \\ ${ }^{1}$ Department of Pathophysiology, School of Basic Medicine Sciences, Nanchang University; \\ ${ }^{2}$ First Clinical Medical School, Nanchang University, Nanchang, Jiangxi 330006, P.R. China
}

Received October 2, 2020; Accepted January 27, 2021

DOI: 10.3892/ijmm.2021.4906

\begin{abstract}
Ovarian granulosa cells (GCs) are the most important source of estrogen. Therefore, aromatase (estrogen synthase), which is the key enzyme in estrogen synthesis, is not only an important factor of ovarian development, but also the key to estrogen secretion by GCs. Disorders of the ovarian estrogen secretion are more likely to induce female estrogen-dependent diseases and fertility issues, such as ovarian cancer and polycystic ovary syndrome. Hence, aromatase is an important drug target; treatment with its inhibitors in estrogen-dependent diseases has attracted increasing attention. The present review article focuses on the regulation and mechanism of the aromatase activity in the GCs, as well as the specific regulation of aromatase promoters. In GCs, follicle-stimulating hormone (FSH) is dependent on the cyclic adenosine monophosphate (cAMP) pathway to regulate the aromatase activity, and the regulation of this enzyme is related to the activation of signaling pathways, such as phosphatidylinositol 3-kinase (PI3K) and extracellular signal-regulated kinase (ERK). In addition, endocrine-disrupting substance and other related factors affect the expression of aromatase,
\end{abstract}

Correspondence to: Dr Hui Lin, Department of Pathophysiology, School of Basic Medicine Sciences, Nanchang University, 461 Bayi Avenue, Nanchang, Jiangxi 330006, P.R. China

E-mail: huilin88@ncu.edu.cn

Abbreviations: AC, adenylate cyclase; AREG, amphiregulin; AMH, Anti-Müllerian hormone; BMP-2, bone morphogenetic protein-2; BPA, bisphenol-A; cAMP, cyclic adenosine monophosphate; DES, diethylstilbestrol; EGF, epidermal growth factor; E2, estradiol; E3, estriol; ESR1, estrogen receptor 1; FSH, follicle-stimulating hormone; HCG, human chorionic gonadotropin; HGF, hepatocyte growth factor; IGF1, insulin-like growth factor 1; LH, luteinizing hormone; MEHP, mono-(2-ethylhexyl) phthalate; CB NPs, carbon black nanoparticles, PRL, prolactin; PI3K, phosphatidylinositol 3-kinase; PCOS, polycystic ovary syndrome; PNE, prenatal nicotine exposure; SF-1, steroidogenic factor-1; TGF- $\beta$, transforming growth factor- $\beta$; TNF, tumor necrosis factor; TCDD, 2,3,7,8-tetrachlorodibenzo-p-dioxin; TZDs, thiazolidinediones; TLR4, Toll-like receptors 4; TH, thyroid hormone

Key words: granulosa cells, aromatase, FSH, cAMP, inhibitor which eventually create an imbalance in the estrogen secretion by the target tissues. The present review highlights these useful factors as potential inhibitors for target therapy.

\section{Contents}

1. Introduction

2. Promoter regulation

3. Aromatase expression localization

4. CYP19A1 is dependent on FSH/cAMP

5. Regulation of aromatase

6. Regulatory pathways of aromatase in GCs

7. Changes in aromatase activity of GCs induce diseases

8. Current and future perspectives

9. Conclusions

\section{Introduction}

Aromatase is a cytochrome P450 monooxygenase that encodes CYP19A1. Its expression is regulated via differential promoter activation in a tissue-specific manner. Aromatase mainly occurs in the ovaries (1), brain cells (2) and testes of rodents (3), as well as in human fat cells (4) and placental cells (5). Under the catalytic action of this enzyme, testosterone and androstenedione become demethylated, causing the A ring to be aromatized, to finally produce estrone and estradiol. Moreover, the transforming aromatase is localized in granulosa cells (GCs) of the ovarian follicles (6). Aromatase plays an important role in GCs. GCs and theca cells synthesize estrogen under the synergy of luteinizing hormone (LH) and follicle-stimulating hormone (FSH). In this process, first, the theca cells synthesize androgens and transfer them to ovarian GCs through the basement membrane, after which the androgens are converted into estrogen through the catalytic action of aromatase. The theory that the two types of cells together with LH and FSH function together in estrogen synthesis is collectively termed as '2-cell, 2-gonadotropin hypothesis' (7). Subsequently, most of the resultant hormone enters the bloodstream and acts on the target organs, such as the breast, while only a small amount of the hormone participates in the ovarian development. GCs are thus extremely important in the process of reproduction; their proliferation and growth determine 
the maturation of follicles and the production of estrogen. In healthy females prior to menopause, human estrogen is mainly derived from ovarian GCs and the placenta, and the expression of P450 aromatase is significantly higher in the GCs than in other tissues (8). Hence, GCs are considered as powerful models for studying aromatase and their mechanisms of action.

Estrogen plays an important role in the female health and fertility status. It is mainly derived from 3 sources: Estrone is mainly converted from androstenedione of the adrenal gland through the skin and adipose tissue $(9,10)$; estradiol (E2), the most widely effective estrogen, is mainly produced by GCs in the ovaries, and is the main estrogen product synthesized before menopause; estriol (E3), the weakest estrogen, is mainly synthesized in the placenta. Since the ovaries are the main organs which secrete estrogen, the normal expression of aromatase is of utmost importance. Presently, the association between aromatase and the ovarian GCs, as well as the regulatory mechanisms of this enzyme in GCs remain undefined. The present review thus focused on aromatase expression and the molecular regulatory mechanisms in ovarian GCs in order to help interpret estrogen disorders. Potential aromatase inhibitors (AIs) are also discussed an effort to open new research avenues for hormone-dependent diseases and fertility treatment influenced by estrogen-secretion disorders (Table I).

\section{Promoter regulation}

The expression of aromatase in different tissues is controlled by distinct promoters, and there are $>10$ promoters that function for selective purposes and tissue specificity. These promoters control the expression of aromatase by recruiting different transcription factors and combining with the cis-regulatory elements (Fig. 1) (11). The transcription of its genes is mainly controlled by the distal promoter I.1 of the placenta (at $40-\mathrm{kb}$ upstream of the translation start site) and the proximal promoter II of the ovary. The aromatase promoter I.4 plays an important role in regulating aromatase expression in the skin; aromatase expression in the adipose tissue is controlled by the ovarian promoter II, as well as by the promoters between I.1 and II (i.e., I.4 and I. 3) (8). The ovaries (promoter II), brain, tissue-specific promoter (If) and bone (promoter I.4 and I.6) are mainly involved in the transcription of the aromatase gene $(12,13)$.

The abnormal regulation of promoters can result in the development of various diseases. For example, promoter transition from I.4 to I.3/II causes the excessive production of estrogen in the breast, rendering breast epithelial cells cancerous, thereby causing breast cancer (11). Similarly, immoderate estrogen secretion due to the mutation in the promoter I.3/II results in endometrial cancer and ovarian cancer, and a cAMP-responsive element (CRE) binding protein (CREB) between promoter I.3/II regulates aromatase through the cAMP/PKA-dependent pathway, which results in the disordered expression of aromatase $(14,15)$.

The transcription of the CYP19A1 promoter in GCs is affected by various factors. Sharma et al reported that, in the buffalo, PII plays a major role in the regulation of CYP19A1 of ovarian GCs, while PI.1 plays a minor role, although PI.1 is transcriptionally upregulated in the luteinization of GCs (16). Previous research has confirmed that ovarian specific I.3 and II can be activated by the majority of phytoestrogens, thereby enhancing the expression level of CYP19A1 mRNA (17). The combination of Jun protein with the CRE near the aromatase promoter PII results in changes in the CRE sites and inhibits the cAMP transcription activation, thereby inhibiting aromatase gene transcription in GCs (18). In addition, in pig GCs, Smad4 combines with the Smad4-binding site (SBE) in the aromatase promoter region as a transcription factor to enhance the expression of CYP19A1 (19). Notably, in the absence of the nuclear receptor element site (NREA) in rabbit GCs, efficient aromatase gene transcription can be performed (20). Previous research has also reported the phenomenon of a novel P450 aromatase promoter in the luteinization of horse GCs treated with human chorionic gonadotropin (HCG), which mainly resulted in the transcriptional upregulation of If promoter and the downregulation of II promoter (21).

\section{Aromatase expression localization}

As mentioned above, the transcription of the aromatase gene is regulated by tissue-specific promoters. This point raises the question of how aromatase is expressed and localized in GCs. The ability of GCs to produce steroids is mainly controlled by FSH. FSH binds to its receptor, and this receptor interacts with adenylate cyclase (AC) to regulate aromatase through the protein kinase A (PKA) pathway (22). In the presence of steroids, the expression of P450arom mRNA in GCs is increased rapidly under the effect of FSH/cAMP (23). The literature confirms that the addition of the C19 steroid substrates (androstenedione and testosterone) to the culture medium of GCs can accelerate the synthesis of estradiol in a concentration- and time-dependent manner (24).

Velthut-Meikas et al for instance, reported 2 origins of introns from the sequencing of mural GCs (MGCs) and cumulus GCs (CGCs) miRNA; one from the FSH receptor gene and the other from CYP19A1, which implies the genome-wide expression of miRNAs in GCs (25). The immunohistochemical localization of aromatase on the ovaries of fillies aged 6-18 months detected aromatase in the mural granulosa of follicles. Moreover, the immunoreactivity of P450arom changes with the size of follicles and disappears in the atretic follicles (26). Observation under an electron and light microscope to locate the aromatase of human ovary and placenta detected that aromatase immune activity occurs mainly in the ovarian granulosa and lutein cells, as well as in a portion of the cytotrophoblast and syncytiotrophoblast of the placenta (27). In addition, aromatase, similar to the locally produced estrogen and androgen, plays an important role in follicular maturation, and the highest expression of aromatase in the GCs occurs in the pre-estrus cycle period (28).

\section{CYP19A1 is dependent on FSH/cAMP}

FSH can regulate the maturation and proliferation of ovarian GCs and binds to the specific receptor FSHR of Sertoli cells and GCs (29). Previous studies have reported that FSH can activate cAMP signaling in vitro or in vivo to enhance the expression of aromatase in ovarian GCs (30-32). FSH is the main factor that stimulates the expression of aromatase 
Table I. Classification of aromatase inhibitors.

\begin{tabular}{llll}
\hline Generation & Type I (steroidal) & Type II (non-steroidal) & Shortcomings \\
\hline First & None & Aminoglutethimide & Low potency, lack of specificity \\
Second & Formestane & Fadrozol, Collettiside & Obvious side-effects, drug resistance \\
Third & Exemestane & Letrozole (Femara) & Less side-effects, (Aromasin) \\
& & Anastrazole (Armida) & Easy to induce osteoarthropathy \\
& Vorozole (Rivizor) & \\
& &
\end{tabular}

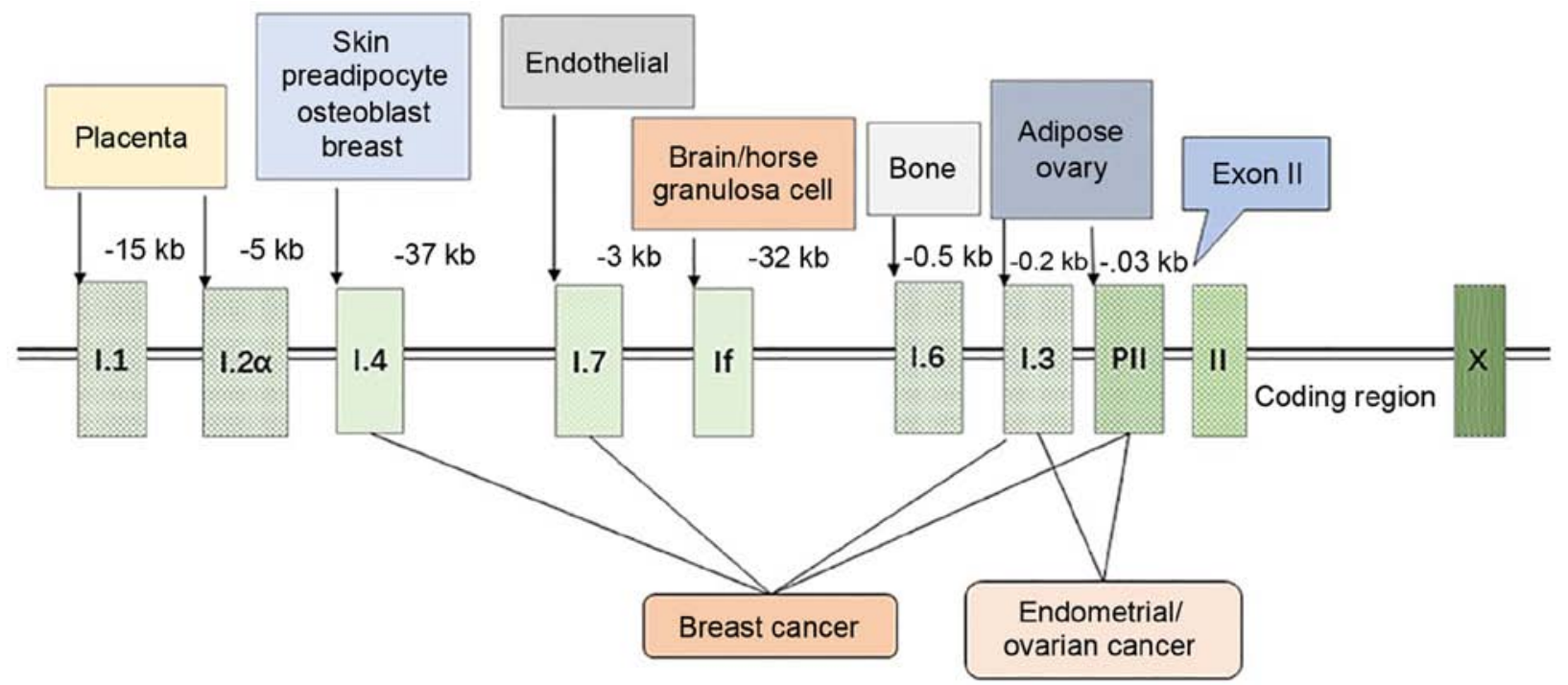

Figure 1. Regulation of aromatase promoters. The expression of aromatase is regulated by tissue-specific promoters, and the figure illustrates the distance between each specific promoter and the first exon II. Breast adipose stromal cells mainly express aromatase through the promoter I.4, while breast cancer tissue use 4 promoters (I.4, I.7, I.3 and II) to regulate aromatase, significantly increasing the expression level of aromatase mRNA and promoting local estrogen production. Endometrial cancer and ovarian cancer are mainly caused by PI.3 and PII, which also lead to a disruption in the expression of aromatase.

CYP19A1. In GCs, it can upregulate the expression of CYP19A1 by activating the transcription factor GATA4. Simultaneously, the activation of GATA4 requires the activation of other kinases, such as ERK1/2, PKA and PI3K (33). Aromatase activity of immature rat GCs increases under the action of FSH and LH (32). E2 can enhance this effect of FSH, which supports the '2-cell, 2-gonadotropin hypothesis' of ovarian synthesis of estrogen. In addition, FSH not only enhances the activity of aromatase in a time-dependent manner, but also enhances the aromatase complex component-flavin protein NADPH-cytochrome $\mathrm{P}-450$ reductase (34). Previous research has reported that Anti-Müllerian hormone (AMH) (35) and virus analog (36) inhibit the increase in aromatase expression and estrogen production induced by FSH. The presence of diethylstilbestrol and androstenedione can enable FSH to increase the expression of aromatase in a dose-dependent manner, leading to increased estrogen secretion. According to the stimulating effect of $\mathrm{FSH}$ on the aromatase activity of rat $\mathrm{GCs}$, it can be used as a biological assay for GC aromatase (37). Moreover, the bone morphogenetic protein (BMP) family plays an important role in human ovarian development; for example, BMP-2 (38), BMP-6 (39) and BMP-7 (40) can reduce the quantity of $\mathrm{LH}$ receptor in hGCs and increase the expression of FSH receptor, while BMP-2 can increase the expression of aromatase in GC cells.

Cyclic adenosine monophosphate (cAMP) can transcriptionally regulate aromatase. The inhibitory effect of progesterone and R5020 on GCs aromatase in rat ovaries has been found to be dose-dependent; moreover, HCG combined with FSH can significantly increase the amount of cAMP and aromatase activity is enhanced at the appropriate concentrations (41). After adenylate cyclase is activated by forskolin, it rapidly, but transiently induces LH-responsive genes [such as the nuclear receptor 4A subfamily; e.g., nerve grow th factor IB (NGFI-B), nuclear receptor-related 1 (NURR1) and neuron-derived orphan receptor 1 (NOR-1)]. However, the ectopic expression of NURR1 or NGFI-B can attenuate the cAMP-responsive activation of the aromatase promoter in KGN cells. Therefore, the expression of aromatase mRNA may be closely related to the induction of nuclear receptor subfamily 4A (42). In addition, luteolin-7-methylether (XLY29) can inhibit the phosphorylation of the cAMP response element binding protein by regulating the expression of aromatase promoter $1.3 / \mathrm{II}$, thereby reducing mouse serum $17 \beta$-estradiol levels (43). The expression of $C Y P 19 A 1$ is thus closely related to the regulation of $\mathrm{FSH} / \mathrm{cAMP}$. 


\section{Regulation of aromatase}

MicroRNAs (miRNAs or miRs). In recent years, miRNAs have become increasingly popular and discovered as drug targets. KGN cells treated with FSH siRNA can induce the differential expression of miR-329-3p, miR-1261, miR-144-5p, miR-130a-3p, miR-185-5p and miR-4463, among which miR-4463 has been found to target the expression of ESR1 and CYP19A1 to influence estradiol secretion (44). In addition, miR-378 (45), miR-10b (19)and miR-1275 (46) combine with the 3 ' untranslated region (3'-UTR) to downregulate the effective transcription of CYP19A1 in ovarian GCs. miR-764-3p can inhibit the expression of CYP19Al by targeting steroidogenic factor-1 (SF-1) to reduce the production of 17 $\beta$-estradiol (47). Through in vitro and in vivo verifications, miR-326 has been found to activate C/EBP- $\beta$ by upregulating CREB, thereby inhibiting the expression of CYP19A1 in buffalo GCs and causing a decrease in the $17 \beta$-estradiol levels (48). Moreover, miR-214-3p has been found to upregulate the expression of cell cycle genes in porcine GCs, but to downregulate the mRNA expression levels of CYP19A1 and steroidogenic acute regulatory protein (StAR) (49). The overexpression of miR-29a in cov434 and KGN cells can cause the expression of aromatase to decrease, affecting the estradiol secretion and inhibiting the cell proliferation (50). In a previous study, a GC model treated with DOX led to the increased expression of miR-132-3p in a dose-dependent manner, as well as in a change in the expression of CYP19A1 and the secretion of 17 $\beta$-estradiol (51).

Growth factors. Aromatase activity in GCs is regulated by various growth factors. Cell location studies have indicated that the insulin-like growth factor-I (IGF1) gene and its receptor gene are highly expressed and translated in ovarian GCs $(52,53)$. IGF1 can increase the production of P-450arom in a concentration-dependent manner and can increase the activity of aromatase. In addition, IGF1 can cooperate with FSH and is more obvious than any hormone alone (54). However, epidermal growth factor (EGF) can inhibit the synthesis of P450 and antagonize FSH. These changes are likely to be related to the mRNA encoding level of aromatase (55). In addition, amphiregulin (AREG) in the EGF-like growth factor induced by HCG can activate the AKT signaling pathway and upregulate the expression of aromatase and estrogen in human granulosa lutein (hGL) cells (56). Moreover, fibroblast growth factor (FGF) and platelet-derived growth factor (PDGF) can reduce the effect of cAMP and may act based on the corresponding tyrosine kinase activity to regulate the synthesis of cytochrome P450 in GCs (57). Some growth factors, such as vascular endothelial growth factor A (VEGF-A) and FGF2 can synergistically promote the expression of CYP19A1 in buffalo GCs and enhance the extent of estradiol secretion (58). Hepatocyte growth factor (HGF) can also inhibit the expression of FSH-induced cAMP-dependent P450arom and 17ß-hydroxysteroid dehydrogenase (HSD), thereby inhibiting GC steroid production in ovarian GCs (59). Transforming growth factor- $\beta$ (TGF- $\beta$ ) has also been reported to enhance the expression of FSH-induced P450arom mRNA in rat GCs (60), as well as accelerate the production of E1 and E2 by 1.45- and 2.7-fold. However, leptin has been reported to antagonize this effect of TGF- $\beta$, which reduces the expression of GC aromatase (61).
Endocrine-disrupting substances. An increasing number of studies have indicated that GCs are easily affected by environmental pollutants in their ability to secrete estrogen. Bisphenol A (BPA), which is industrially used as a plasticizer, has been reported to decrease the aromatase expression in GC cell-line KGN stimulated by FSH to reduce the estradiol secretion, which may function by inducing peroxisome proliferator-activated receptor- $\gamma$ (PPAR $\gamma)(62,63)$. In rats, 2,3,7,8-tetrachlorodibenzo-p-dioxin (TCDD) may reduce the aromatase mRNA expression in GCs through the AHR/ARNT signaling pathway, causing a decrease in the estradiol secretion $(64,65)$. TCDD may also directly or indirectly block the endocrine function of human luteinized GCs (hLGCs) through the interaction of PTK/MAP2K and PKA signaling $(66,67)$. Plasticizer mono-(2-ethylhexyl) phthalate and its metabolite mono-(2-ethylhexyl) phthalate (MEHP) also reduce the transcription of aromatase in human and rat GCs, and thereby reduce the secretion of estradiol (68-70). Recently, it was reported that carbon black nanoparticles (CB NPs) can inhibit the transcription level of aromatase in GCs by activating the ERK1/2 pathway and influencing E2 secretion. In addition, PD98059 signals can inhibit the ERK1/2 signaling pathway to reduce the adverse effects of CB NPs (71). In addition, prenatal nicotine exposure (PNE) can reduce histone 3 lysine 27 acetylation (H3K27ac) and H3K9ac of P450arom in the ovarian GC cell line, KGN, through nicotine acetylcholine receptor (nAChR), which consequently results in the reduction of the aromatase expression and estradiol production in the ovaries (72). In GCs, lead may affect female fertility by downregulating the transcription of estrogen receptor $\beta$ (ER $\beta)$ and $p 450$ arom (73).

Morinaga et al also evaluated aromatase activity in KGN cells and screened 55 endocrine-disrupting chemicals (74). For the first time, they proved that benomyl and its metabolite carbendazim can enhance aromatase activity through the regulation of the transcription level, possibly through a microtubule interference mechanism rather than through the cAMP-PKA pathway (74). In addition, 2,2-bis-(p-hydroxyphenyl)-1,1,1-trichloroethane (HPTE) has been reported to inhibit the increase in the expression of P450arom mRNA, P450scc and 3 $\beta-\mathrm{HSD}$ in FSH-cultured GCs, albeit it had no effect on StAR. HPTE also affected the cAMP site of action and may therefore involve a broad steroid regulation of the cAMP-PKA pathway (75). Endocrine-disrupting substances are thus likely to affect human reproduction and sexual differentiation by modifying the steroid secretion properties of GCs.

Insulin sensitizers. Metformin is an insulin sensitizer with direct function in the ovaries, which may downregulate the expression of aromatase promoter I.4, I.3 and II through the MEK/ERK pathway, thereby reducing the aromatase activity in GCs (76). In addition, the expression of aromatase mRNA decreases in human luteinized GCs cultured with metformin, although it can significantly increase the effect of insulin on IGF1R mRNA and IR (77). Pioglitazone or rosiglitazone can inhibit estrogen production in human ovarian GCs by interfering with the combination of aromatase and androgens, and the effect of thiazolidinediones (TZDs) in reducing the activity of aromatase may explain the application of TZD in the treatment of estrogen-dependent diseases and polycystic ovary 
syndrome (PCOS) (78). Troglitazone is also a compound of TZDs that is likely to exert a direct inhibitory effect on aromatase in GCs through the nuclear receptor system PPAR $\gamma / \mathrm{RXR}$ heterodimer (79). Insulin sensitizers thus have a probable potential as effective inhibitors of aromatase that warrant further investigation (Table II).

\section{Regulatory pathways of aromatase in GCs}

cAMP/PKA pathway. In GCs, cAMP is the second messenger of FSH, and cAMP inducers and cAMP analogs can induce multiple functions of GCs in vitro (80). LH receptor expression is regulated by the combined action of estradiol and FSH; therefore, in the cultured rat GCs, the induction of FSH can make the cells respond to $\mathrm{LH}$, thereby enhancing the overall aromatase activity (81). LH and FSH exert their biological functions through the mediation of $\mathrm{G}$ protein-coupled receptors LHCGR and FSHR, thereby causing the activation of several signaling cascades, such as the cyclic AMP/protein kinase A (cAMP/PKA) pathway (82). On binding with the corresponding receptors in GCs, LH and FSH activate the Gs protein on the cell membrane, resulting in the production of cAMP. Therefore, they activate the cAMP-dependent PKA signaling pathway and act on the expression of CYP19A1, which is a classic PKA-dependent aromatase regulation pathway (13).

PI3K. The rapid activation of the PKA signaling pathway also induces other cascading reactions. For example, FSH can promote the activation of PI3K signaling in the rat GCs and cause the rapid phosphorylation of its downstream branch point, AKT; as a result, the expression of ovarian genes such as CYP19A1 increases (80). Moreover, it can enhance the activity of HIF-1 downstream of the PI3K/AKT/Raheb/mammalian target of rapamycin (mTOR) pathway in GCs (83). IGF1 has been confirmed to be an important molecule for hormone synthesis in GCs (76); it can activate PI3K/Akt, which upregulates FSH receptor. When Akt and PKA are activated, they regulate the expression of CYP19AI (84). It has previously been confirmed that the molecular mechanism of 3,5,3'-tri-iodothyronine (T3) regulates the expression of CYP19A1 in GC and promotes follicle development. The combination of FSH and T3 requires the activation of the PI3K/Akt pathway to regulate CYP19A1. Therefore, CYP19A1 is likely to be a downstream effector of the PI3K/Akt pathway that is activated by FSH and T3, which acts as a new mediator for FSH and T3 to induce the development of GCs and follicles, while regulating FSH and TH (85).

ERK. The surge of LH prior to ovulation can rapidly inhibit the proliferation of GCs and differentiate them into luteal cells. However, the proper dose of LH can also cause the rapid activation of ERK1/2 when acting on GCs, while FSH also have the same effect (86). ERK, similar to PKA, is a downstream signaling molecule involved in the action of LH and FSH. This point raises a question of whether aromatase is regulated as a downstream molecule of this signaling pathway. Huang et al used PD98059 to block the hormone-stimulated MEK1 in KGN cells and found that 17-hydroxylase/17,20 lyase (CYP17) expression increased, and that the expression of
P450 aromatase (CYP19) and c-fos also decreased (87). Hence, c-fos is likely to be downstream of the MEK/ERK pathway, and CYP19 is upregulated and CYP17 is downregulated in GCs, which together inhibit the production of estradiol (87).

Others. Activin can enhance the aromatase activity of FSH in the rat GCs (88). Nomura et al confirmed the mechanisms action in KGN cells (89). Moreover, Smad2 is downstream of activin-type IB receptor (ActRIB); it participates in the activin-signaling pathway to regulate the expression of $\mathrm{P} 450$ aromatase, thereby regulating the follicular development (89). In addition, LPS-induced Toll-like receptor 4 (TLR4) signaling can downregulate the expression of CYP19A1 and 17 $\beta$-estradiol in bovine GCs under the action of CCAAT/enhancer binding protein beta (CEBPB) (90). Notably, Notch signaling affects the secretion of estrogen by affecting the expression of the upstream transcription factors, Wt1, SF-1, GATA4 and GATA6, and that of downstream-related enzymes related to steroid production (91). The research on the mechanism of aromatase regulation in GCs is thus ongoing and not yet concrete (Fig. 2).

\section{Changes in aromatase activity of GCs induce diseases}

Aromatase is the only enzyme in vertebrates that catalyzes the production of estrogen. The disruption of estrogen secretion can thus easily cause cancer of the breast, endometrium or ovaries, which are together referred to as 'estrogen-dependent tumors' (92). These tumors can also cause female reproductive issues. GCs are the main source of ovarian estrogen secretion, which not only induces ovarian development but also releases estrogen into the blood and supply it to various organs. Therefore, whether the secretion of GCs aromatase is normal directly affects the health status of various organs. Nowadays, the inhibition of aromatase-induced estrogen biosynthesis is considered to be the main strategy for the therapy of estrogen-dependent diseases. Considering that the aromatase status of patients with recurrent granulosa cell tumors remains unaltered, the detection of the expression of aromatase can provide more accurate information for serum E2 in the primary tumor as a relapse marker (93).

Ovarian GC tumors are one of the most common ovarian tumors, mainly causing abnormal estrogen secretion (94) (Fig. 3). In normal GCs, FSH binds to its receptor to activate Gs protein and upregulate the aromatase expression through the PKA pathway. However, mutations in the Gs protein on the cell membrane are likely to induce the production of cancerous cells (95). The forkhead family FOXL2 is an evolutionarily conserved member of the transcription factor; its mutation is closely related to the generation of ovarian GC tumor (96). Smad3 can cooperate with FOXL2:C134W in combination with the CYP19A1 promoter FBE5 of the human $\mathrm{GC}$ line ( $\mathrm{HGrCl})$ to enhance the expression of aromatase, which is probably the key reason for the large amount of estrogen secretion by the human GC line (97). The mutation of FOXL2:C134W is the main reason for the formation of adult ovarian granulosa cell tumor (GCT); it can enhance the induction of aromatase by FOXL2, and aromatase is the direct target of FOXL2:C134W (98). This information deepens our understanding of the research on the pathogenesis of the adult GC tumor. 
Table II. Potential aromatase inhibitors.

\begin{tabular}{|c|c|c|c|c|}
\hline Classification & Molecules & Mechanism of action & Species & (Refs.) \\
\hline \multirow[t]{8}{*}{ MicroRNAs } & $\operatorname{miR}-4463$ & Target the expression of ESR 1 and CYP19A1 & Human & $(42)$ \\
\hline & $\operatorname{miR}-378$ & Downregulate the transcription of CYP19A1 & Pig & $(45)$ \\
\hline & $\operatorname{miR}-10 b$ & Combines with 3'-UTR & Pig & $(45)$ \\
\hline & $\operatorname{miR}-1275$ & Combines with 3'-UTR & Pig & $(45)$ \\
\hline & $\operatorname{miR}-764-3 p$ & By targeting SF-1 & Mouse & $(47)$ \\
\hline & $\operatorname{miR}-326$ & Activate $\mathrm{C} / \mathrm{EBP}-\beta$ by upregulating $\mathrm{CREB}$ & Buffalo & $(48)$ \\
\hline & $\operatorname{miR}-214-3 p$ & Downregulated CYP19A1 and StAR & Pig & $(48)$ \\
\hline & $\operatorname{miR}-29 a$ & Decrease aromatase expression & Human & $(50)$ \\
\hline \multirow[t]{4}{*}{ Hormones } & $\mathrm{AMH}$ & Inhibit the effect of FSH on estrogen production & Pig & $(42)$ \\
\hline & $\mathrm{R} 5020$ & Dose-dependent inhibition & Rat & $(41)$ \\
\hline & Progesterone & Dose-dependent inhibition & Rat & $(41)$ \\
\hline & Leptin & Antagonism TGF $\beta$ & Rat & $(61)$ \\
\hline \multirow[t]{4}{*}{ Growth factor } & EGF & Suppress the effects of FSH and cAMP & Human & $(116)$ \\
\hline & FGF & Reduce the role of cAMP & Human & $(57)$ \\
\hline & PDGF & Reduce the role of cAMP & Human & $(57)$ \\
\hline & HGF & Destruction of FSH-induced cAMP-mediated & Rat & $(59)$ \\
\hline \multirow[t]{4}{*}{ Insulin sensitizers } & Metformin & Downregulate the aromatase promoter & Human & $(76)$ \\
\hline & Rosiglitazone & Reduce the effect of aromatase & Human & $(78)$ \\
\hline & Pioglitazone & Reduce the effect of aromatase & Human & $(78)$ \\
\hline & Troglitazone & Through nuclear receptor system & Human & $(79)$ \\
\hline
\end{tabular}

ESR1, estrogen receptor 1; SF-1, steroidogenic factor-1; StAR, steroidogenic acute regulatory protein; AMH, anti-Müllerian hormone; EGF, epidermal growth factor; FGF, fibroblast growth factor; PDGF, platelet-derived growth factor; HGF, Hepatocyte growth factor.

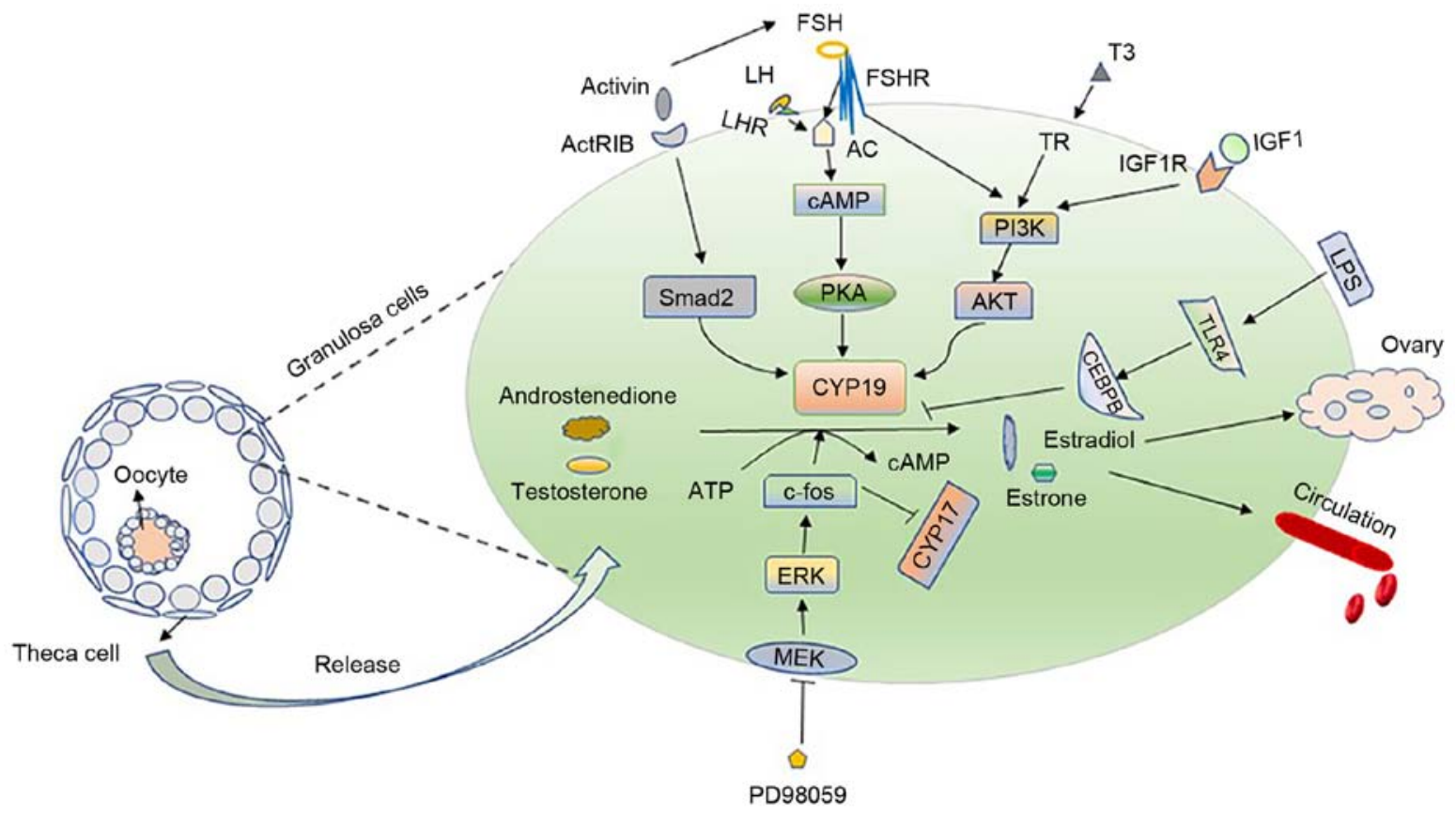

Figure 2. Regulatory mechanism of aromatase and '2-cell, 2-gonadotropin hypothesis'. The left panel illustrates that follicles are mainly composed of oocytes, granulosa cells and theca cells. Androstenedione and androsterone secreted by theca cells penetrate into granulosa cells and are converted into estrone and estradiol by the aromatase in granulosa cells under the stimulation of FSH and LH hormones. A small part acts on the ovaries, and the majority is released into the blood, collectively referred to as the '2-cell, 2-gonadotropin hypothesis'. The right panel mainly introduces the regulatory mechanism of aromatase in granulosa cells. FSH and LH bind to receptors and regulate CYP19A1 through PKA pathway. At the same time, IGF-1 binds to its receptor to activate PI3K/Akt, which upregulates the expression of CYP19; T3 cooperates with FSH also to acts on aromatase via PI3K/AKT pathway. The inhibition of the hormone-stimulated ERK with PD98059 can act on c-fos, causing the upregulation of $C Y P 19$ and the downregulation of $C Y P 17$. LH, luteinizing hormone; FSH, follicle-stimulating hormone; ERK, extracellular signal-regulated kinase; PI3K, phosphoinositide 3-kinase; PKA, protein kinase A; cAMP, cyclic adenosine monophosphate; CEBPB, CCAAT/enhancer-binding protein beta. 


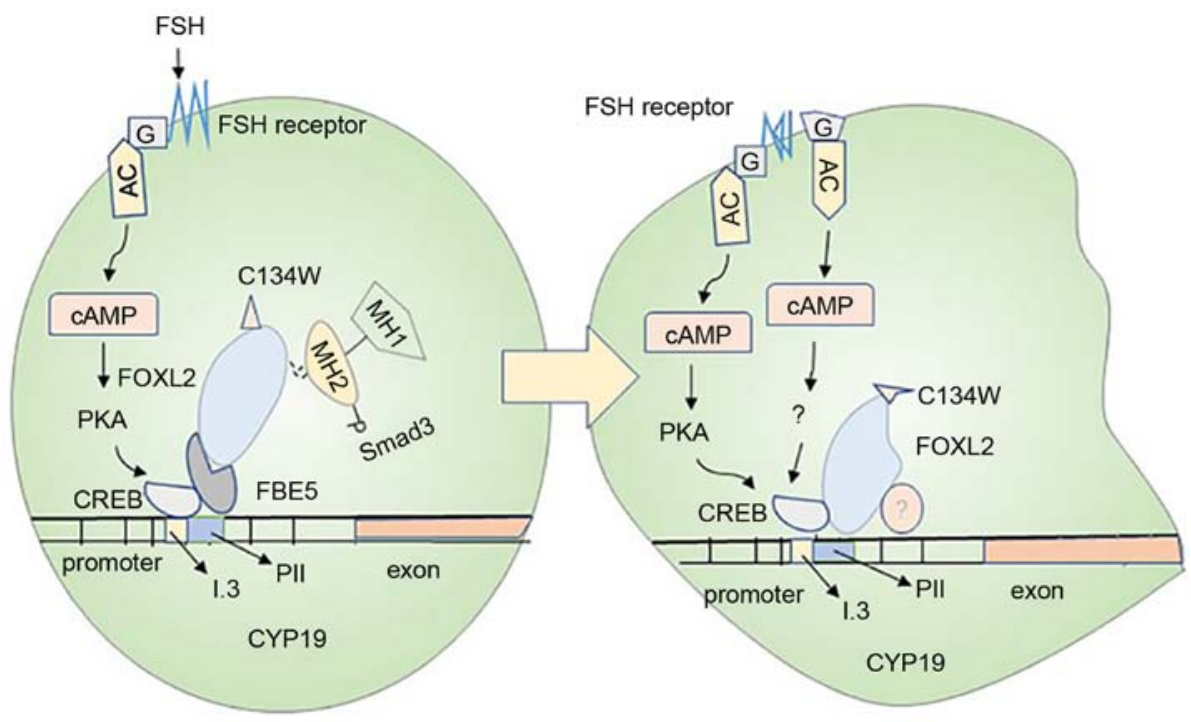

Granulosa cells

Granulosa cell tumor

Figure 3. Mechanisms of ovarian granulosa cell carcinogenesis. The normal granulosa cells shown in the left panel and the cancerous granulosa cells shown in the right panel mainly introduce the carcinogenesis mechanism of the cells. In normal granulosa cells, FSH binds to the receptor and acts through the trimer $\mathrm{G}$ protein $(\mathrm{G})$ and adenylate cyclase, then, combine to the CRE binding site of CYP19A1 through the protein kinase A pathway, causing increased expression of aromatase. In the granulosa cells on the right, the FSH may not depend on the activation of this pathway, and the cancerization mainly originates from the mutation of the trimer G protein $(G)$ and the activation of the FSH receptor. In addition, Smad3 in normal granulosa cells cooperates with FOXL2:C134W and FBE5 to act on $C Y P 19 A 1$ gene. The mutant FOXL2:C134W in granulosa cell tumors binds to another specific site of $C Y P 19$ and recruits unknown proteins, causing cell mutations. These are likely to cause abnormal expression of aromatase in granulosa cells and cancerization of cells. FSH, follicle-stimulating hormone; cAMP, cyclic adenosine monophosphate; PKA, protein kinase A; CREB, cAMP-response element binding protein.

The abnormal secretion of estradiol from the GCs can result in abnormalities in the target organs, such as the breast and uterus (Fig. 4). Based on the literature, the expression levels of aromatase in the diseased tissues of the endometrium and breast are significantly higher than those in normal tissues (99), with adult ovarian cancer patients being more prone to endometrial and breast cancer (100). In addition, the increased expression of aromatase can also induce endometriosis and uterine fibroids in females. In granulosa cells, SF-1 can bind to the cAMP response element and act on aromatase promoter II, thereby causing estrogen production (101). Abnormally expressed SF-1 in endometriosis will compete with the aromatase expression inhibitor-chicken ovalbumin upstream promoter-transcription factor (COUP-TF) for the same binding site, thereby stimulating the activity of aromatase P450 (102). Moreover, glucocorticoids and IL1 $\beta$ can affect the secretion of estrogen by regulating the expression of aromatase promoter 1.4 , thereby affecting the occurrence of uterine fibroids (103).

The estrogen secretion disorder, which induces increase in the incidence of PCOS, is the main cause of female infertility (104). PCOS is mainly manifested as a disease of the reproductive dysfunction and endocrine disorders, which is mainly characterized by the high levels of androgens and anovulation. The hyperandrogenic state of the ovaries of patients with PCOS is the main risk factor for the decline of aromatase production in luteinized GCs (105). It has been reported that androgens can enhance the FSH effect in granulosa cells by increasing FSHR. When androgen secretion is excessive, the high sensitivity of GCs to FSH causes a large increase in $\mathrm{AMH}$, and $\mathrm{AMH}$ in turn inhibits the effect of FSH on aromatase in follicles (106). Recently, Che et al (107) found that the highly expressed lncRNA HUPCOS of granulosa cells in patients with PCOS can interact with RNA-binding protein with multiple splicing (RBPMS) and inhibit the expression of aromatase, thereby mediating the excess of androgen in the follicular fluid of PCOS patients Therefore, the decrease in the aromatase activity conversely helps maintain high androgen levels (102,107). In addition, CYP19A1 and A-Kinase anchor protein 95 (AKAP95) levels are significantly decreased in human luteinized GCs of patients with PCOS. AKAP95 is thus likely to act on FSH-stimulated CYP19A1 (108). All of these participate in the pathological mechanism of PCOS. Moreover, the abnormal expression of aromatase mRNA in GCs can also induce obesity in women, which is an important factor affecting female fertility. It has been reported that leptin can induce neuropeptide cocaine- and amphetamine-regulated transcript (CART) in GCs, thereby indirectly inhibiting the cAMP levels and the aromatase expression in GCs, causes ovarian dysfunction and reduced fertility (109).

\section{Current and future perspectives}

Environmental pollution and modification in diets are considered to be important elements affecting female fertility and health issues. Several diseases have been confirmed in relation to estrogen-secretion disorders in the epidemiology and experimental studies. In some patients with estrogen-dependent diseases, high levels of estrogen are accompanied by the overexpression of aromatase (15). For example, in breast cancer treatment, multiple AIs have been developed, such as exemestane, anastrozole, letrozole and vorozole. The current first-line treatment for breast cancer mainly uses third-generation AIs $(110,111)$. In addition, AIs have begun to be used in 


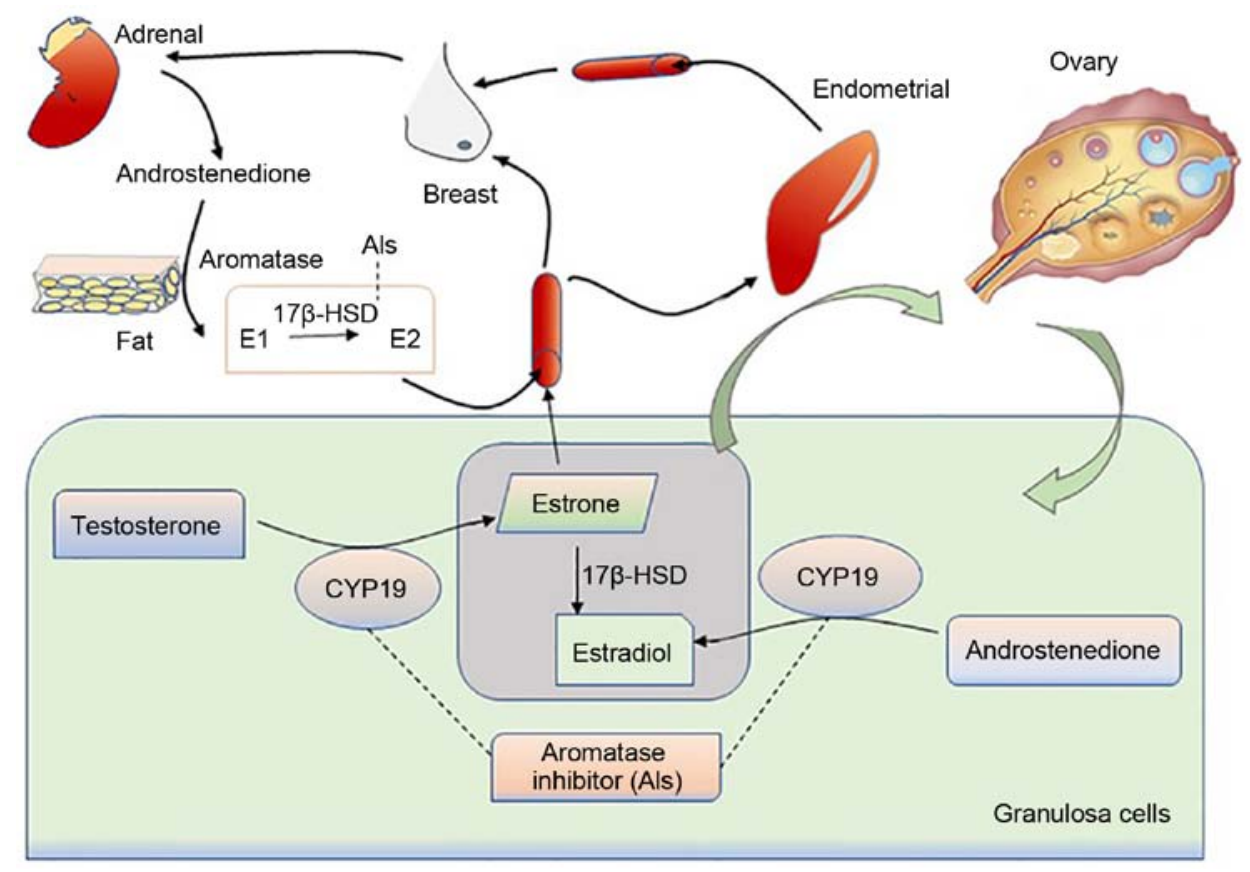

Figure 4. Source of estrogen production and the site of aromatase inhibitor action. In granulosa cells, under the action of aromatase, androstenedione and androsterone can be converted into estradiol and estrone. A small part of the secreted estrogen acts on the development of the ovaries; the majority is released into the blood circulation and enter the uterus, breast, kidney and other target tissues. In addition to the estrogen source of granulosa cells, androstenedione secreted by the adrenal glands can be converted to E1 in tissues such as fat, then it is converted into E2 under the action of 17-HSD, and finally acts on each target tissue from the blood circulation. The uncontrolled regulation of aromatase will cause estrogen secretion disorder, and even cause endocrine disorders of ovarian, uterine, breast and other target tissues, and even cancer. However, aromatase inhibitors can downregulate the highly expressed CYP19A1 and interrupt the conversion of androgens and androstenedione to estrogen, thus exerting a therapeutic effect on some estrogen-dependent diseases.

the treatment of estrogen-regulated diseases, such as ovarian cancer and endometrial cancer, as well as inducing ovulation. Presently, AIs combined with progesterone and $\mathrm{GnRH}$ agonists are mainly used to treat women with endometriosis, along with reducing the risk of ovarian cysts induced by AIs alone. However, symptoms, such as pelvic pain may recur following AI treatment. For women with polycystic ovary syndrome and obesity, letrozole has a higher live birth rate compared with clomiphene citrate, and it has been regarded as the first-line therapy of inducing ovulation. Moreover, AIs are also a good first choice for women with infertility due to the presence of uterine fibroids, the wish to preserve the uterus, or being unsuitable for surgery (112).

Although AIs are effective in the treatment of estrogen-dependent diseases and ovulation induction, osteoarthropathy, menopausal symptoms, intestinal discomfort and drug resistance, which are easily induced following treatment with AIs, remain concerns which require resolutions. A recent study designed and synthesized a novel aromatase inhibitor based on triazole and imidazole (113). However, the current inhibitors are mainly used in the treatment of breast cancer, albeit for other steroid-dependent diseases and female infertility, and there are a relatively few effective and specific drugs available $(114,115)$, which indicates that the search for novel AIs and other effective drug targets is crucial.

GCs, which are the main site of ovarian estrogen production, also generate a large amount of aromatase. Aromatase can promote the biosynthesis of estrogen in GCs, and the production of estrogen can promote the follicular development of GCs and inhibit the apoptosis of GCs. The transcription of genes is mainly controlled by the distal promoter I.1 of the placenta (at $40 \mathrm{~kb}$ upstream of the translation start site) and the proximal promoter II of the ovary (8). FSH can regulate the expression of aromatase by activating the PKA signaling pathway, while simultaneously activating the PI3K (85), ERK (87) and other signaling pathways, thereby upregulating the expression of CYP19A1. The disadvantage of this approach is the lack of substantial research supporting whether the transient activation of P38MAPK caused by FSH can also regulate the expression of aromatase. In addition, owing to biodiversity, individual differences exist in the regulation of aromatase due to different factors, which may present new areas of interest in future research. Understanding the molecular modifications and the mechanisms of action in GCs that can be targeted in the disorders of aromatase secretion for the treatment of diseases caused by ovarian hormones is expected to develop high-efficiency, low-toxic, and side effects of specific drug targets.

\section{Conclusions}

The present article summarized and discussed the regulatory characteristics of the CYP19A1 promoter in ovarian GCs, as well as the regulation of aromatase as a downstream effector through multiple signaling pathways. The expression of aromatase in GCs is affected by various factors, and it is one of the main causes of estrogen-dependent diseases and PCOS. Endocrine-disrupting substances in the environment can cause alteration in the expression of aromatase and affect the normal reproduction and sexual differentiation in the human body. Furthermore, some insulin sensitizers have been developed as AIs for the clinical treatment. Other substances, such as FSH, 
IGF-1 and TGF $\beta$ have been proven to promote the expression of aromatase mRNA and protein, although miRNAs, HGF and leptin can partially inhibit or specifically identify the aromatase promoter and downregulate the aromatase transcription, leading to the disturbance in estrogen secretion. Thus, the discovery of potential aromatase inhibitor targets is expected to provide new directions for the treatment of estrogen-dependent diseases and PCOS.

\section{Acknowledgements}

Not applicable.

\section{Funding}

The present study was supported by grants from the National Natural Science Foundation of China (no. 31900852 to HL), Nanchang University (no. PY201801 to HL) and the Natural Science Foundation of Jiangxi Province (nos. 2018BAB215012 and 20192ACB21026 to HL).

\section{Availability of data and materials}

Not applicable.

\section{Authors' contributions}

HL, TL and YH designed and wrote the manuscript. All authors have read and approved the final manuscript.

\section{Ethics approval and consent to participate}

Not applicable.

\section{Patient consent for publication}

Not applicable.

\section{Competing interests}

The authors declare that they have no competing interests.

\section{References}

1. Mendelson CR, Jiang B, Shelton JM, Richardson JA and Hinshelwood MM: Transcriptional regulation of aromatase in placenta and ovary. J Steroid Biochem Mol Biol 95: 25-33, 2005.

2. Li J and Gibbs RB: Detection of estradiol in rat brain tissues: Contribution of local versus systemic production. Psychoneuroendocrinology 102: 84-94, 2019.

3. Lambard S, Silandre D, Delalande C, Denis-Galeraud I, Bourguiba S and Carreau S: Aromatase in testis: Expression and role in male reproduction. J Steroid Biochem Mol Biol 95: 63-69, 2005.

4. Mahendroo MS, Mendelson CR and Simpson ER: Tissue-specific and hormonally controlled alternative promoters regulate aromatase cytochrome $\mathrm{P} 450$ gene expression in human adipose tissue. J Biol Chem 268: 19463-19470, 1993.

5. Wang Y, Pan P, Li X, Zhu Q, Huang T and Ge RS: Food components and environmental chemicals of inhibiting human placental aromatase. Food Chem Toxicol 128: 46-53, 2019.

6. Ai A, Tang Z, Liu Y, Yu S, Li B, Huang H, Wang X, Cao Y and Zhang W: Characterization and identification of human immortalized granulosa cells derived from ovarian follicular fluid. Exp Ther Med 18: 2167-2177, 2019.
7. Shoham Z, Jacobs HS and Insler V: Luteinizing hormone: Its role, mechanism of action, and detrimental effects when hypersecreted during the follicular phase. Fertil Steril 59: 1153-1161, 1993.

8. Nelson LR and Bulun SE: Estrogen production and action. J Am Acad Dermatol 45 (Suppl 3): S116-S124, 2001.

9. Slominski A, Zbytek B, Nikolakis G, Manna PR, Skobowiat C, Zmijewski M, Li W, Janjetovic Z, Postlethwaite A, Zouboulis CC and Tuckey RC: Steroidogenesis in the skin: Implications for local immune functions. J Steroid Biochem Mol Biol 137: 107-123, 2013.

10. Bulun SE, Chen D, Moy I, Brooks DC and Zhao H: Aromatase, breast cancer and obesity: A complex interaction. Trends Endocrinol Metab 23: 83-89, 2012.

11. Zhao H, Zhou L, Shangguan AJ and Bulun SE: Aromatase expression and regulation in breast and endometrial cancer. J Mol Endocrinol 57: R19-R33, 2016.

12. Shozu M, Zhao Y and Simpson ER: TGF-beta1 stimulates expression of the aromatase (CYP19) gene in human osteoblast-like cells and THP-1 cells. Mol Cell Endocrinol 160: 123-133, 2000.

13. Stocco C: Aromatase expression in the ovary: Hormonal and molecular regulation. Steroids 73: 473-487, 2008.

14. Bulun SE, Chen D, Lu M, Zhao H, Cheng Y, Demura M, Yilmaz B, Martin R, Utsunomiya H, Thung S, et al: Aromatase excess in cancers of breast, endometrium and ovary. J Steroid Biochem Mol Biol 106: 81-96, 2007.

15. Bulun SE and Simpson ER: Aromatase expression in women's cancers. Adv Exp Med Biol 630: 112-132, 2008.

16. Sharma D, Ghai S and Singh D: Different promoter usage for CYP19 gene expression in buffalo ovary and placenta. Gen Comp Endocrinol 162: 319-328, 2009.

17. Solak KA, Wijnolts FMJ, Nijmeijer SM, Blaauboer BJ, van den Berg M and van Duursen MBM: Excessive levels of diverse phytoestrogens can modulate steroidogenesis and cell migration of KGN human granulosa-derived tumor cells. Toxicol Rep 1: 360-372, 2014

18. Ghosh S, Wu Y, Li R and Hu Y: Jun proteins modulate the ovary-specific promoter of aromatase gene in ovarian granulosa cells via a cAMP-responsive element. Oncogene 24: 2236-2246, 2005.

19. Li Q, Du X, Pan Z, Zhang L and Li Q: The transcription factor SMAD4 and miR-10b contribute to E2 release and cell apoptosis in ovarian granulosa cells by targeting CYP19A1. Mol Cell Endocrinol 476: 84-95, 2018

20. Andrieu T, Féral C, Joubert M, Benhaim A and Mittre H: The absence of a functional nuclear receptor element A (NREA) in the promoter II of the aromatase P450 gene in rabbit granulosa cells. J Steroid Biochem Mol Biol 101: 127-135, 2006.

21. Boerboom D, Kerban A and Sirois J: Dual regulation of promoter II- and promoter 1f-derived cytochrome P450 aromatase transcripts in equine granulosa cells during human chorionic gonadotropin-induced ovulation: A novel model for the study of aromatase promoter switching. Endocrinology 140: 4133-4141, 1999.

22. Simpson ER: Sources of estrogen and their importance. J Steroid Biochem Mol Biol 86: 225-230, 2003.

23. Miyoshi T, Otsuka F and Shimasaki S: GRK-6 mediates FSH action synergistically enhanced by estrogen and the oocyte in rat granulosa cells. Biochem Biophys Res Commun 434: 401-406, 2013.

24. Czajka-Oraniec I and Simpson ER: Aromatase research and its clinical significance. Endokrynol Pol 61: 126-134, 2010.

25. Velthut-Meikas A, Simm J, Tuuri T, Tapanainen JS, Metsis M and Salumets A: Research resource: Small RNA-seq of human granulosa cells reveals miRNAs in FSHR and aromatase genes. Mol Endocrinol 27: 1128-1141, 2013.

26. Mlodawska W and Slomczynska M: Immunohistochemical localization of aromatase during the development and atresia of ovarian follicles in prepubertal horses. Theriogenology 74 : 1707-1712, 2010.

27. Naganuma $\mathrm{H}$, Ohtani $\mathrm{H}, \mathrm{Harada} \mathrm{N}$ and Nagura $\mathrm{H}$ : Immunoelectron microscopic localization of aromatase in human placenta and ovary using microwave fixation. J Histochem Cytochem 38: 1427-1432, 1990.

28. Shaikh AA: Estrone and estradiol levels in the ovarian venous blood from rats during the estrous cycle and pregnancy. Biol Reprod 5: 297-307, 1971.

29. Szymańska K, Kałafut J, Przybyszewska A, Paziewska B, Adamczuk G, Kiełbus M and Rivero-Müller A: FSHR trans-activation and oligomerization Front Endocrinol (Lausanne) 9: 760, 2018. 
30. Jiang C, Hou X, Wang C, May JV, Butnev VY, Bousfield GR and Davis JS: Hypoglycosylated hFSH has greater bioactivity than fully glycosylated recombinant hFSH in human granulosa cells. J Clin Endocrinol Metab 100: E852-E860, 2015.

31. Hobeika E, Armouti M, Kala H,Fierro MA, Winston NJ, Scoccia B, Zamah AM and Stocco C: Oocyte-secreted factors synergize with FSH to promote aromatase expression in primary human cumulus cells. J Clin Endocrinol Metab 104: 1667-1676, 2019.

32. Parakh TN, Hernandez JA, Grammer JC, Weck J, HunzickerDunn M, Zeleznik AJ and Nilson JH: Follicle-stimulating hormone/cAMP regulation of aromatase gene expression requires beta-catenin. Proc Natl Acad Sci USA 103: 12435-12440, 2006.

33. Kwintkiewicz J, Cai Z and Stocco C: Follicle-stimulating hormone-induced activation of Gata4 contributes in the up-regulation of Cyp19 expression in rat granulosa cells. Mol Endocrinol 21: 933-947, 2007.

34. Hong Y, Li H, Yuan YC and Chen S: Molecular characterization of aromatase. Ann N Y Acad Sci 1155: 112-120, 2009.

35. Li Y, Gao D, Xu T, Adur MK, Zhang L, Luo L, Zhu T, Tong X, Zhang D, Wang Y, et al: Anti-Müllerian hormone inhibits luteinizing hormone-induced androstenedione synthesis in porcine theca cells. Theriogenology 142: 421-432, 2020.

36. Fang Y, Wang B, Lyu S, Zhang K, Cheng Q and Zhu Y: Virus analog decreases estradiol secretion in FSH-treated human ovarian granulosa cells. Gynecol Endocrinol 36: 346-350, 2020.

37. Kajitani T, Liu S, Maruyama T, Uchida H, Sakurai R, Masuda H, Nagashima T, Ono M, Arase T and Yoshimura Y: Analysis of serum FSH bioactivity in a patient with an FSH-secreting pituitary microadenoma and multicystic ovaries: A case report. Hum Reprod 23: 435-439, 2008.

38. Shi J, Yoshino O, Osuga Y, Koga K, Hirota Y, Nose E, Nishii O, Yano T and Taketani Y: Bone morphogenetic protein-2 (BMP-2) increases gene expression of FSH receptor and aromatase and decreases gene expression of LH receptor and StAR in human granulosa cells. Am J Reprod Immunol 65: 421-427, 2011.

39. Shi J, Yoshino O, Osuga Y, Koga K, Hirota Y, Hirata T, Yano T, Nishii $\mathrm{O}$ and Taketani Y: Bone morphogenetic protein- 6 stimulates gene expression of follicle-stimulating hormone receptor, inhibin/activin beta subunits, and anti-Müllerian hormone in human granulosa cells. Fertil Steril 92: 1794-1798, 2009.

40. Shi J, Yoshino O, Osuga Y, Nishii O, Yano T and Taketani Y: Bone morphogenetic protein 7 (BMP-7) increases the expression of follicle-stimulating hormone (FSH) receptor in human granulosa cells. Fertil Steril 93: 1273-1279, 2010.

41. Overes HW, de Leeuw R and Kloosterboer HJ: Regulation of aromatase activity in FSH-primed rat granulosa cells in vitro by follicle-stimulating hormone and various amounts of human chorionic gonadotrophin. Hum Reprod 7: 191-196, 1992.

42. Wu Y, Ghosh S, Nishi Y, Yanase T, Nawata H and Hu Y: The orphan nuclear receptors NURR1 and NGFI-B modulate aromatase gene expression in ovarian granulosa cells: A possible mechanism for repression of aromatase expression upon luteinizing hormone surge. Endocrinology 146: 237-246, 2005.

43. Du BW, Zhang XJ, Shi N, Peng T, Gao JB, Azimova B, Zhang R, $\mathrm{Pu} \mathrm{DB}$, Wang $\mathrm{C}$, Abduvaliev A, et al: Luteolin-7-methylether from Leonurus japonicus inhibits estrogen biosynthesis in human ovarian granulosa cells by suppression of aromatase (CYP19). Eur J Pharmacol 879: 173154, 2020.

44. Lee SY, Kang YJ, Kwon J, Nishi Y, Yanase T, Lee KA and Koong MK: miR-4463 regulates aromatase expression and activity for $17 \beta$-estradiol synthesis in response to follicle-stimulating hormone. Clin Exp Reprod Med 47: 194-206, 2020.

45. Xu S, Linher-Melville K, Yang BB, Wu D and Li J: Micro-RNA378 (miR-378) regulates ovarian estradiol production by targeting aromatase. Endocrinology 152: 3941-3951, 2011

46. Liu J, Li X, Yao Y, Li Q, Pan Z and Li Q: miR-1275 controls granulosa cell apoptosis and estradiol synthesis by impairing LRH-1/CYP19A1 axis. Biochim Biophys Acta Gene Regul Mech 1861: 246-257, 2018

47. Wang L, Li C, Li R, Deng Y, Tan Y, Tong C and Qi H MicroRNA-764-3p regulates $17 \beta$-estradiol synthesis of mouse ovarian granulosa cells by targeting steroidogenic factor-1. In Vitro Cell Dev Biol Anim 52: 365-373, 2016.

48. Chaurasiya V, Kumari S, Onteru SK and Singh D: miR-326 down-regulate CYP19A1 expression and estradiol-17b production in buffalo granulosa cells through CREB and C/EBP- $\beta$. J Steroid Biochem Mol Biol 199: 105608, 2020.

49. Shi S, Zhou X, Li J, Zhang L, Hu Y, Li Y, Yang G and Chu G: MiR-214-3p promotes proliferation and inhibits estradiol synthesis in porcine granulosa cells. J Anim Sci Biotechnol 11: 94, 2020.
50. Li Y, Liu YD, Zhou XY, Chen SL, Chen X, Zhe J, Zhang J, Zhang QY and Chen YX: MiR-29a regulates the proliferation, aromatase expression, and estradiol biosynthesis of human granulosa cells in polycystic ovary syndrome. Mol Cell Endocrinol 498: 110540, 2019.

51. Al-Kawlani B, Murrieta-Coxca JM, Chaiwangyen W, Fröhlich K, Fritzsche A, Winkler S, Markert UR and Morales-Prieto DM: Doxorubicin induces cytotoxicity and miR-132 expression in granulosa cells. Reprod Toxicol 96: 95-101, 2020.

52. Ogo Y, Taniuchi S, Ojima F, Hayashi S, Murakami I, Saito Y, Takeuchi S, Kudo T and Takahashi S: IGF-1 gene expression is differentially regulated by estrogen receptors $\alpha$ and $\beta$ in mouse endometrial stromal cells and ovarian granulosa cells. J Reprod Dev 60: 216-223, 2014.

53. Zhou J, Chin E and Bondy C: Cellular pattern of insulin-like growth factor-I (IGF-I) and IGF-I receptor gene expression in the developing and mature ovarian follicle. Endocrinology 129: 3281-3288, 1991.

54. Mani AM, Fenwick MA, Cheng Z, Sharma MK, Singh D and Wathes DC: IGF1 induces up-regulation of steroidogenic and apoptotic regulatory genes via activation of phosphatidylinositol-dependent kinase/AKT in bovine granulosa cells. Reproduction 139: 139-151, 2010.

55. Herrmann M, Scholmerich J and Straub RH: Influence of cytokines and growth factors on distinct steroidogenic enzymes in vitro: A short tabular data collection. Ann NY Acad Sci 966: 166-186, 2002.

56. Fang L, Yu Y, Li Y, Wang S, Zhang R, Guo Y, Li Y, Yan Y and Sun YP: Human chorionic gonadotropin-induced amphiregulin stimulates aromatase expression in human granulosa-lutein cells: A mechanism for estradiol production in the luteal phase. Hum Reprod 34: 2018-2026, 2019.

57. Mendelson CR, Merrill JC, Steinkampf MP and Simpson ER: Regulation of the synthesis of aromatase cytochrome P-450 in human adipose stromal and ovarian granulosa cells. Steroids 50: 51-59, 1987

58. Mishra SR, Bharati J, Rajesh G, Chauhan VS, Taru Sharma G, Bag S, Maurya VP, Singh G and Sarkar M: Fibroblast growth factor 2 (FGF2) and vascular endothelial growth factor A (VEGFA) synergistically promote steroidogenesis and survival of cultured buffalo granulosa cells. Anim Reprod Sci 179: 88-97, 2017.

59. Zachow RJ, Ramski BE and Lee H: Modulation of estrogen production and 17beta-hydroxysteroid dehydrogenase-type 1 , cytochrome $\mathrm{P} 450$ aromatase, c-met, and protein kinase Balpha messenger ribonucleic acid content in rat ovarian granulosa cells by hepatocyte growth factor and follicle-stimulating hormone. Biol Reprod 62: 1851-1857, 2000.

60. Chen YJ, Hsiao PW, Lee MT, Mason JI, Ke FC and Hwang JJ: Interplay of PI3K and CAMP/PKA signaling, and rapamycin-hypersensitivity in TGFbetal enhancement of FSH-stimulated steroidogenesis in rat ovarian granulosa cells. J Endocrinol 192: 405-419, 2007.

61. Zachow RJ, Weitsman SR and Magoffin DA: Leptin impairs the synergistic stimulation by transforming growth factor-beta of follicle-stimulating hormone-dependent aromatase activity and messenger ribonucleic acid expression in rat ovarian granulosa cells. Biol Reprod 61: 1104-1109, 1999.

62. Kwintkiewicz J, Nishi Y, Yanase T and Giudice LC: Peroxisome proliferator-activated receptor-gamma mediates bisphenol A inhibition of FSH-stimulated IGF-1, aromatase, and estradiol in human granulosa cells. Environ Health Perspect 118: 400-406, 2010.

63. Bloom MS, Mok-Lin E and Fujimoto VY: Bisphenol A and ovarian steroidogenesis. Fertil Steril 106: 857-863, 2016

64. Dasmahapatra AK, Wimpee BA, Trewin AL and Hutz RJ: 2,3,7,8-Tetrachlorodibenzo-p-dioxin increases steady-state estrogen receptor-beta mRNA levels after CYP1A1 and CYP1B1 induction in rat granulosa cells in vitro. Mol Cell Endocrinol 182: 39-48, 2001.

65. Dasmahapatra AK, Wimpee BA, Trewin AL, Wimpee CF, Ghorai JK and Hutz RJ: Demonstration of 2,3,7,8-tetrachlorodibenzo-p-dioxin attenuation of P450 steroidogenic enzyme mRNAs in rat granulosa cell in vitro by competitive reverse transcriptase-polymerase chain reaction assay. Mol Cell Endocrinol 164: 5-18, 2000.

66. Enan E, Moran F, VandeVoort CA, Stewart DR, Overstreet JW and Lasley BL: Mechanism of toxic action of 2,3,7,8-tetrachlorodibenzo-p-dioxin (TCDD) in cultured human luteinized granulosa cells. Reprod Toxicol 10: 497-508, 1996. 
67. Baldridge MG, Marks GT, Rawlins RG and Hutz RJ: Very low-dose (femtomolar) 2,3,7,8-tetrachlorodibenzo-p-dioxin (TCDD) disrupts steroidogenic enzyme mRNAs and steroid secretion by human luteinizing granulosa cells. Reprod Toxicol 52: 57-61, 2015.

68. Lovekamp TN and Davis BJ: Mono-(2-ethylhexyl) phthalate suppresses aromatase transcript levels and estradiol production in cultured rat granulosa cells. Toxicol Appl Pharmacol 172: 217-224, 2001

69. Reinsberg J, Wegener-Toper P, van der Ven K, van der Ven $\mathrm{H}$ and Klingmueller D: Effect of mono-(2-ethylhexyl) phthalate on steroid production of human granulosa cells. Toxicol Appl Pharmacol 239: 116-123, 2009.

70. Davis BJ, Weaver R, Gaines LJ and Heindel JJ: Mono-(2-ethylhexyl) phthalate suppresses estradiol production independent of FSH-cAMP stimulation in rat granulosa cells. Toxicol Appl Pharmacol 128: 224-228, 1994.

71. Simon V, Avet C, Grange-Messent V, Wargnier R, Denoyelle C, Pierre A, Dairou J, Dupret JM and Cohen-Tannoudji J: Carbon black nanoparticles inhibit aromatase expression and estradiol secretion in human granulosa cells through the ERK1/2 pathway. Endocrinology 158: 3200-3211, 2017.

72. Fan G, Zhang Q, Wan Y, Lv F, Chen Y, Ni Y, Zou W, Zhang W and Wang H: Decreased levels of H3K9ac and H3K27ac in the promotor region of ovarian $\mathrm{P} 450$ aromatase mediated low estradiol synthesis in female offspring rats induced by prenatal nicotine exposure as well as in human granulosa cells after nicotine treatment. Food Chem Toxicol 128: 256-266, 2019.

73. Taupeau C, Poupon J, Treton D, Brosse A, Richard Y and Machelon V: Lead reduces messenger RNA and protein levels of cytochrome p450 aromatase and estrogen receptor beta in human ovarian granulosa cells. Biol Reprod 68: 1982-1988, 2003.

74. Morinaga H, Yanase T, Nomura M, Okabe T, Goto K, Harada N and Nawata $\mathrm{H}$ : A benzimidazole fungicide, benomyl, and its metabolite, carbendazim, induce aromatase activity in a human ovarian granulose-like tumor cell line (KGN). Endocrinology 145: 1860-1869, 2004.

75. Zachow R and Uzumcu M: The methoxychlor metabolite, 2,2-bis-(p-hydroxyphenyl)-1,1,1-trichloroethane, inhibits steroidogenesis in rat ovarian granulosa cells in vitro. Reprod Toxicol 22: 659-665, 2006.

76. Rice S, Pellatt L, Ramanathan K, Whitehead SA and Mason HD: Metformin inhibits aromatase via an extracellular signal-regulated kinase-mediated pathway. Endocrinology 150: 4794-4801, 2009.

77. Fuhrmeister IP, Branchini G, Pimentel AM, Ferreira GD, Capp E, Brum IS and von Eye Corleta H: Human granulosa cells: Insulin and insulin-like growth factor-1 receptors and aromatase expression modulation by metformin. Gynecol Obstet Invest 77: $156-162,2014$

78. Seto-Young D, Avtanski D, Parikh G, Suwandhi P, Strizhevsky M Araki T, Rosenwaks Z and Poretsky L: Rosiglitazone and pioglitazone inhibit estrogen synthesis in human granulosa cells by interfering with androgen binding to aromatase. Horm Metab Res 43: 250-256, 2011.

79. Mu YM, Yanase T, Nishi Y, Waseda N, Oda T, Tanaka A, Takayanagi R and Nawata H: Insulin sensitizer, troglitazone, directly inhibits aromatase activity in human ovarian granulosa cells. Biochem Biophys Res Commun 271: 710-713, 2000.

80. Gonzalez-Robayna IJ, Falender AE, Ochsner S, Firestone GL and Richards JS: Follicle-Stimulating hormone (FSH) stimulates phosphorylation and activation of protein kinase $\mathrm{B}(\mathrm{PKB} / \mathrm{Akt})$ and serum and glucocorticoid-lnduced kinase (Sgk): Evidence for A kinase-independent signaling by FSH in granulosa cells. Mol Endocrinol 14: 1283-1300, 2000

81. Donadeu FX and Ascoli M: The differential effects of the gonadotropin receptors on aromatase expression in primary cultures of immature rat granulosa cells are highly dependent on the density of receptors expressed and the activation of the inositol phosphate cascade. Endocrinology 146: 3907-3916, 2005

82. Riccetti L, Sperduti S, Lazzaretti C, Casarini L and Simoni M The cAMP/PKA pathway: Steroidogenesis of the antral follicular stage. Minerva Ginecol 70: 516-524, 2018.

83. Alam H, Maizels ET, Park Y, Ghaey S, Feiger ZJ, Chandel NS and Hunzicker-Dunn M: Follicle-stimulating hormone activation of hypoxia-inducible factor-1 by the phosphatidylinositol 3-kinase/AKT/Ras homolog enriched in brain (Rheb)/mammalian target of rapamycin (mTOR) pathway is necessary for induction of select protein markers of follicular differentiation. J Biol Chem 279: 19431-19440, 2004.
84.Zhou Y, Zeng C, Li X, Wu PL, Yin L, Yu XL, Zhou YF and Xue Q: IGF-I stimulates ER $\beta$ and aromatase expression via IGF1R/PI3K/AKT-mediated transcriptional activation in endometriosis. J Mol Med (Berl) 94: 887-897, 2016.

85. Liu J, Han Y, Tian Y, Weng X, Hu X, Liu W, Heng D, Xu K, Yang Y and Zhang C: Regulation by 3,5,3'-tri-iodothyronine and FSH of cytochrome P450 family 19 (CYP19) expression in mouse granulosa cells. Reprod Fertil Dev 30: 1225-1233, 2018.

86. Cottom J, Salvador LM, Maizels ET, Reierstad S, Park Y, Carr DW, Davare MA, Hell JW, Palmer SS, Dent P, et al: Follicle-stimulating hormone activates extracellular signal-regulated kinase but not extracellular signal-regulated kinase kinase through a 100-kDa phosphotyrosine phosphatase. J Biol Chem 278: 7167-7179, 2003.

87. Huang X, Jin J, Shen S, Xia Y, Xu P, Zou X, Wang H, Yi L, Wang Y and Gao Q: Modulation of expression of 17-Hydroxylase/17,20 lyase (CYP17) and P450 aromatase (CYP19) by inhibition of MEK1 in a human ovarian granulosa-like tumor cell line. Gynecol Endocrinol 32: 201-205, 2016.

88. Findlay JK: An update on the roles of inhibin, activin, and follistatin as local regulators of folliculogenesis. Biol Reprod 48: $15-23,1993$

89. Nomura M, Sakamoto R, Morinaga H, Wang L, Mukasa C and Takayanagi R: Activin stimulates CYP19A gene expression in human ovarian granulosa cell-like KGN cells via the Smad2 signaling pathway. Biochem Biophys Res Commun 436: 443-448, 2013

90. Yenuganti VR, Ravinder and Singh D: Endotoxin induced TLR4 signaling downregulates CYP19A1 expression through CEBPB in buffalo granulosa cells. Toxicol In Vitro 42: 93-100, 2017.

91. Wang Y, Lu E, Bao R, Xu P, Feng F, Wen W, Dong Q, Hu C, Xiao L, Tang M, et al: Notch signalling regulates steroidogenesis in mouse ovarian granulosa cells. Reprod Fertil Dev 31: 1091-1103, 2019

92. Manna PR, Molehin D and Ahmed AU: Dysregulation of aromatase in breast, endometrial, and ovarian cancers: An overview of therapeutic strategies. Prog Mol Biol Transl Sci 144: 487-537, 2016.

93. Kato N, Uchigasaki S, Fukase M and Kurose A: Expression of P450 aromatase in granulosa cell tumors and sertoli-stromal cell tumors of the ovary: Which cells are responsible for estrogenesis? Int J Gynecol Pathol 35: 41-47, 2016.

94. Kitamura S, Abiko K, Matsumura N, Nakai H, Akimoto Y, Tanimoto $\mathrm{H}$ and Konishi I: Adult granulosa cell tumors of the ovary: A retrospective study of 30 cases with respect to the expression of steroid synthesis enzymes. J Gynecol Oncol 28: e31, 2017

95. Hsueh AJ, Adashi EY, Jones PB and Welsh TH Jr: Hormonal regulation of the differentiation of cultured ovarian granulosa cells. Endocr Rev 5: 76-127, 1984.

96. Cocquet J, Pailhoux E, Jaubert F, Servel N, Xia X, Pannetier M, De Baere E, Messiaen L, Cotinot C, Fellous M and Veitia RA: Evolution and expression of FOXL2. J Med Genet 39: 916-921, 2002.

97. Belli M, Iwata N, Nakamura T, Iwase A, Stupack D and Shimasaki S: FOXL2C134W-induced CYP19 expression via cooperation with SMAD3 in $\mathrm{HGrC1}$ cells. Endocrinology 159: 1690-1703, 2018.

98. Fleming NI, Knower KC, Lazarus KA, Fuller PJ, Simpson ER and Clyne CD: Aromatase is a direct target of FOXL2: C134W in granulosa cell tumors via a single highly conserved binding site in the ovarian specific promoter. PLoS One 5: e14389, 2010.

99. Leung K: (S)-6-[(4-Chlorophenyl)(1H-1,2,4-triazol-1-yl) methyl]-1-[(11)C $]$ methyl-1H-benzotriazole. In: Molecular imaging and contrast agent database (MICAD). National Center for Biotechnology Information, Bethesda, MD, 2004.

100. Moro F, Leombroni M, Pasciuto T, Trivellizzi IN, Mascilini F, Ciccarone F, Zannoni GF, Fanfani F, Scambia G and Testa AC: Synchronous primary cancers of endometrium and ovary vs endometrial cancer with ovarian metastasis: An observational study. Ultrasound Obstet Gynecol 53: 827-835, 2019.

101. Michael MD, Kilgore MW, Morohashi K and Simpson ER: Ad4BP/SF-1 regulates cyclic AMP-induced transcription from the proximal promoter (PII) of the human aromatase P450 (CYP19) gene in the ovary. J Biol Chem 270: 13561-13566, 1995.

102. Panghiyangani R, Soeharso P, Andrijono, Suryandari DA, Wiweko B, Kurniati M and Pujianto DA: CYP19A1 gene expression in patients with polycystic ovarian syndrome. J Hum Reprod Sci 13: 100-103, 2020. 
103. Shozu M, Sumitani H, Segawa T, Yang HJ, Murakami K, Kasai $\mathrm{T}$ and Inoue M: Overexpression of aromatase P450 in leiomyoma tissue is driven primarily through promoter I.4 of the aromatase P450 gene (CYP19). J Clin Endocrinol Metab 87: 2540-2548, 2002.

104. Jamnongjit M and Hammes SR: Ovarian steroids: The good, the bad, and the signals that raise them. Cell Cycle 5: 1178-1183, 2006.

105. Yang F, Ruan YC, Yang YJ, Wang K, Liang SS, Han YB, Teng XM and Yang JZ: Follicular hyperandrogenism downregulates aromatase in luteinized granulosa cells in polycystic ovary syndrome women. Reproduction 150: 289-296, 2015.

106. Dewailly D, Robin G, Peigne M, Decanter C, Pigny P and Catteau-Jonard S: Interactions between androgens, FSH, anti-Müllerian hormone and estradiol during folliculogenesis in the human normal and polycystic ovary. Hum Reprod Update 22: 709-724, 2016.

107. Che Q, Liu M, Zhang D, Lu Y, Xu J, Lu X, Cao X, Liu Y, Dong X and Liu S: Long noncoding RNA HUPCOS promotes follicular fluid androgen excess in PCOS patients via aromatase inhibition. J Clin Endocrinol Metab 105: dgaa060, 2020.

108. Gu Y, Xu W, Zhuang B and Fu W: Role of A-kinase anchoring protein 95 in the regulation of cytochrome P450 family 19 subfamily A member 1 (CYP19A1) in human ovarian granulosa cells. Reprod Fertil Dev 30: 1128-1136, 2018.

109. MaX, Hayes E, Prizant H, Srivastava RK, Hammes SR and Sen A: Leptin-induced CART (cocaine- and amphetamine-regulated transcript) is a novel intraovarian mediator of obesity-related infertility in females. Endocrinology 157: 1248-1257, 2016.
110. Turkistani A and Marsh S: Pharmacogenomics of third-generation aromatase inhibitors. Expert Opin Pharmacother 13: 1299-1307, 2012.

111. Kharb R, Haider K, Neha K and Yar MS: Aromatase inhibitors: Role in postmenopausal breast cancer. Arch Pharm (Weinheim) 353: e2000081, 2020.

112. Usluogullari B, Duvan C and Usluogullari C: Use of aromatase inhibitors in practice of gynecology. J Ovarian Res 8: 4, 2015.

113. Ammazzalorso A, Gallorini M, Fantacuzzi M, Gambacorta N, De Filippis B, Giampietro L, Maccallini C, Nicolotti O, Cataldi A and Amoroso R: Design, synthesis and biological evaluation of imidazole and triazole-based carbamates as novel aromatase inhibitors. Eur J Med Chem 211: 113115, 2021.

114. Haltia UM, Pihlajoki M, Andersson N, Mäkinen L, Tapper J, Cervera A, Horlings HM, Turpeinen U, Anttonen M, Bützow R, et al: Functional profiling of FSH and estradiol in ovarian granulosa cell tumors. J Endocr Soc 4: bvaa034, 2020.

115. Ghosh D, Lo J and Egbuta C: Recent progress in the discovery of next generation inhibitors of aromatase from the structurefunction perspective. J Med Chem 59: 5131-5148, 2016.

116. Steinkampf MP, Mendelson CR and Simpson ER: Effects of epidermal growth factor and insulin-like growth factor I on the levels of mRNA encoding aromatase cytochrome P-450 of human ovarian granulosa cells. Mol Cell Endocrinol 59: 93-99, 1988.

This work is licensed under a Creative Commons Attribution-NonCommercial-NoDerivatives 4.0 International (CC BY-NC-ND 4.0) License. 